\title{
Directly observed treatment increases drug compliance in lymphatic filariasis mass drug administration
}

\author{
Tutik Ida Rosanti***, Sugeng Juwono Mardihusodo***, and Wayan T. Artama****
}

\section{ABSTRACT}

\section{BACKGROUD.}

Mass drug administration (MDA) has been one of the strategies for lymphatic filariasis elimination. Since the start of implementation in 2011 in Pekalongan, no study on MDA acceptability has yet been done. The objectives of the study were to determine the microfilaria rate ( $\mathrm{mf}$ rate) and the risk factors of drug compliance in the MDA program.

\section{METHODS}

A longitudinal study was conducted at Pabean region, Pekalongan City. There were 90 household heads as subjects, who were selected by proportional cluster random sampling. Microfilaria rate (mf rate) was determined by finger blood examination. Drug compliance was measured using questionnaires and observation sheets. Drug compliance observers, filariasis counseling participation, and presence of filariasis patients were factors influencing drug compliance.

\section{RESULTS}

Mf rate in 2015 was $1.35 \%$ and drug compliance rate was $86.80 \%$. Reasons for failing to take drugs were fear of side effects (50\%), refusals $(25 \%)$, laziness $(16.7 \%)$, and perceiving the drug to be useless $(8.3 \%)$. The chisquare test shows a significant difference between the presence of drug compliance observer and compliance $(\mathrm{p}=0.006)$. Filariasis counseling participation and presence of filariasis patients did not show a significant difference with drug compliance $(\mathrm{p}=0.986)$.

\section{CONCLUSIONS}

Families as the source of observers was associated with increased filariasis drug compliance. It is therefore essential to address the issues linked to low compliance to make the program more efficient and achieve the goal of filariasis elimination.

Keywords: Filariasis, medical compliance, mass drug administration
*Postgraduate Program,

Faculty of Medicine, Gadjah Mada

University, Yogyakarta

**Department of Parasitology

Faculty of Medicine

Jenderal Soedirman University

***Department of Parasitology,

Faculty of Medicine,

Gadjah Mada University, Yogyakarta

****Faculty of Veterinary Medicine,

Gadjah Mada University, Yogyakarta

Correspondence:

dr. Tutik Ida Rosanti, M.Kes.

Department of Parasitology

Faculty of Medicine

Jenderal Soedirman University

Jl. Dr. Gumbreg no.1

Purwokerto - Jawa Tengah

Mobile: +628112600 255

Email: tutikidarosanti@yahoo.com

Univ Med 2016;35:119-27

DOI: 10.18051/UnivMed.2016.v35.89-95 pISSN: 1907-3062 / eISSN: 2407-2230

This open access article is distributed under a Creative Commons Attribution-Non

Commercial-Share Alike 4.0 International License 


\section{INTRODUCTION}

Lymphatic filariasis or elephanthiasis is a chronic communicable disease that is caused by filarial worms infecting the lymphatics and lymph nodes. The disease is marked by the clinical symptoms of swelling of the hands, feet, and scrotum, and causes life-long disability and disfigurement to the patients. Although it is not fatal, this disease causes economic loss and social stigmatization for the patients, family and country. ${ }^{(1)}$

To date, lymphatic filariasis still constitutes a public health problem in Indonesia and the world. Indonesia is one of the 11 countries endemic for lymphatic filariasis in South East Asia with an average prevalence rate of $19 \%$, distributed over 337 districts /cities. ${ }^{(2)}$

Pekalongan is one of the cities with endemic lymphatic filariasis in Central Java with Wuchereria bancrofti as causative organism and Culex quinquefasciatus mosquitoes as vectors. ${ }^{(3)}$ Fingerprick blood surveys (FBS) in 2010 showed that several kelurahan (villages) had high microfilaria (mf) rates of $5.54 \%, 2.39 \%, 3.39 \%$, and $2.39 \%$ in the kelurahan of Bumirejo, Tegalrejo, Pabean, and Bandengan, respectively. ${ }^{\left({ }^{3}\right)}$

As an endemic area of lymphatic filariasis, Pekalongan has carried out mass drug administration (MDA) for filariasis since 2011. The purpose of mass drug administration for filariasis is to eliminate filariasis by treating the source of infection, namely persons who have microfilaria in their blood. The presence of microfilaria in the blood of patients is a source of infection for other individual in the neighborhood and for the mosquito vectors of filariasis. The transmission of filariasis may be reduced or inhibited through elimination of microfilarial reservoirs by means of mass drug administration and reducing contact between humans and the vectors. ${ }^{(4)}$ Mass drug administration in the filariasis elimination program in Indonesia aims to interrupt filariasis transmission by reducing the $\mathrm{mf}$ rate to less than $1 \%$ and reducing mean microfilarial density. ${ }^{(5)}$
Mass drug administration for the elimination of lymphatic filariasis is the strategy of interrupting the filariasis transmission chain by a single annual administration of dietylcarbamazine citrate (DEC) tablets to all individuals above 2 years of age. The coverage and compliance levels are important to inhibit transmission for a period of 4-6 years, which is the mean reproduction time of adult filarial worms. ${ }^{(6)}$

A study by Karoma et al. ${ }^{(7)}$ reported that upon instituting the third MDA round, the program succeeded in reducing the $\mathrm{mf}$ rate by $88.5 \%$, from $2.6 \%$ to $0.3 \%$ and in reducing mean microfilarial density by $17.59 \mathrm{mf} / \mathrm{mL}$, whereas the study by Eigege et al. ${ }^{(8)}$ showed that a $90 \%$ reduction in $\mathrm{mf}$ rate from $3.17 \%$ to $0.32 \%$ only occurred after implementation of the $8^{\text {th }}$ MDA round.

A systematic review in India identified a coverage-compliance gap in many MDA programs, along with potentially correctable causes. Overall MDA coverage rates ranged from $48.8 \%$ to $98.8 \%$ and compliance rates from $20.8 \%$ to $93.7 \%$. Among $31 \mathrm{MDAs}$, there were only 10 with a compliance level of e" $65 \%$ (five of 20 MDAs in rural and two of 12 MDAs in urban areas). ${ }^{(9)}$ Another study showed that $99 \%$ of the study participants received DEC and albendazole tablets during MDA, of which only just above a quarter actually consumed the drugs. ${ }^{(10)}$ The gap between MDA coverage rates and compliance rates, as reported in previous studies, needs to be subjected to further reasearch to find the causative factors. The purpose of the present study was to assess the impact of the MDA program and determine the factors associated with noncompliance in taking antifilariasis drugs.

\section{METHODS}

\section{Study design}

This was a longitudinal study that was carried out from September 2014 until May 2015.

\section{Study subjects}

The study subjects were residents of an area with chronic filariasis patients and were recorded 
as recipients of antifilariasis drugs in the filariasis mass drug administration program for the years 2014 and 2015. Mass drug administration for filariasis was performed under the coordination of the Pekalongan City Health Service, in accordance with the WHO recommendations, namely using a single dose of diethyl carbamazine citrate (DEC) (three $100 \mathrm{mg}$ tablets for persons weighing $50 \mathrm{~kg}$ ) with the addition of a single 400 $\mathrm{mg}$ dose of albendazole. The population for the assessment of filariasis drug compliance included all household heads (if there was no household head, he or she was represented by a household member) who were residents of the Pabean region, North Pekalongan District, Pekalongan City, and comprised 1378 households. Sample size calculation was by means of the minimal sample size formula: ${ }^{(11)}$

$$
\mathrm{n}=\frac{\mathrm{z}^{2}{ }_{1-\alpha / z} \mathrm{P}(1-\mathrm{P}) \mathrm{N}}{\mathrm{d}^{2}(\mathrm{~N}-1)+\mathrm{z}_{1-\alpha / z}^{2} \mathrm{P}(1-\mathrm{P})}
$$

According to the formula, if $\mathrm{p}$ (estimated prevalence of filariasis drug taking practice $)=$ 0.5 and $\mathrm{d}$ (precision) $=0.1$, then the minimal sample size was 89.90 , which with the addition of possible drop outs became 91 . The sample was recruited by proportional cluster random sampling. The sample size for each RT was determined using the formula according to Sugiyono, ${ }^{(12)}$ i.e.

$$
\mathrm{n}=\frac{\mathrm{x}}{\mathrm{N}} \times \mathrm{N}_{1}
$$

Based on this formula, the obtained sample size for RT 2 RW I was 10 household heads, for RT 4 RW I 12 household heads, RT 3 RW II 7 household heads, RT 1 RW III 29 household heads, RT 2 RW III 16 household heads, and RT 1 RW IV 17 household heads. The samples were determined based on an interval with the formula: $\mathrm{i}=\frac{\mathrm{N}}{\mathrm{n}}$

Based on this formula, the samples were determined with an interval between 5 to 6 .

\section{Data collection procedures}

The questionnaire comprised personal data of the study subjects (name, age, gender, address, presence/absence of chronic disease, pregnant/ non-pregnant, lactating/non-lactating), reasons for drug noncompliance, variables associated with drug compliance in the MDA program (the presence of drug compliance observers, type of the drug compliance observers, history of participation in filariasis counseling, and the presence of chronic filariasis patients in the residential area of the study subjects).

Drug compliance observers were persons who reminded the study subjects to take the antifilariasis drugs distributed by Puskesmas (community health center) personnel, observed the subjects swallowing the drugs, and reported eventual occurrence of side effects. Drug compliance observers comprised health cadres and family members. Observation sheets were used to record the results of observation of the study subjects regarding their compliance in taking antifilariasis drugs. The compliance in taking antifilariasis drugs in the filariasis mass drug administration program was determined by interviews and filling-in of observation sheets. Observation of drug compliance was performed by the investigators assisted by 5 trained health cadres and 5 personnel of Dukuh puskesmas, Pekalongan City. Before performing the interviews and filling-in of observation sheets, comprehension and equality of perception was checked for each question and observation item.

\section{Laboratory examination}

Equipment and materials used in the determination of $\mathrm{mf}$ rate consisted of microscope glass slides, blood lancets, tissue paper rolls, alcohol swabs, gloves, slide boxes, Giemsa stock solution, measuring glasses, survey forms, dropper pipettes, pencils, $\mathrm{Aqua}^{\mathrm{R}}$ bottled water for preparing Giemsa solution.

The sample size for the $\mathrm{mf}$ rate determination was 300 persons. The sample was recruited by gathering the residents who were the survey targets and resided in the neighborhood of clinical cases of bancroftian filariasis. The identification of microfilariae in the blood used the FBS technique. The sample 
collection was performed in the Pabean region in the neighborhood of clinical cases of bancroftian filariasis at night, from 21.00 up to 01.00 Western Indonesian Time. The blood samples were collected from the tips of the second or third fingers, which were pricked with sterile lancets until bleeding. The first drop of blood was swabbed away and the next three drops of blood $(60 \mu \mathrm{L})$ were placed on a clean glass slide. Subsequently the blood was spread out with the corner of another slide. The blood slide was left to air-dry overnight at room temperature and subsequently stained with Giemsa.

The $\mathrm{mf}$ rate was calculated by dividing the number of residents whose blood were positive for microfilariae by the number of examined blood slides multiplied by one hundred percent. The FBS population comprised adults who had resided in the area for 2 years or more.

\section{Statistical analysis}

Univariate analysis was performed on variables of respondents' characteristics, consisting of age, gender, compliance in taking antifilariasis drugs in the years 2014 and 2015, accompanied with reasons for drug noncompliance, and type of drug compliance observer. The $\mathrm{mf}$ rates for the years 2014 and 2015 were expressed as percentages of reductions or increases.

Bivariate analysis on the variables presence of drug compliance observer, history of subject participation in filariasis counseling, and the presence of patients with chronic filariasis in the neighborhood of the homes of the study subjects, in relation to drug compliance in the filariasis MDA program was performed using the chisquare test.

\section{Ethical clearance}

Written informed was obtained from all respondents, while keeping their identities confidential. The study was conducted after obtaining ethical clearance from the Ethics Commission, Faculty of Medicine, Gadjah Mada University, Yogyakarta, with reference no. KE/ FK/869/EC.

\section{RESULTS}

After filariasis mass drug administration, i.e.the $4^{\text {th }}$ year of MDA program, there occured a reduction in $\mathrm{mf}$ of $3,57 \%$ from $1.4 \%$ to $.35 \%$, while in 2015 , a reduction in $\mathrm{mf}$ rate of $76.29 \%$ occurred, changing form $1.35 \%$ to $0.32 \%$.

According to Table 1, the majority (18 or $19.8 \%$ ) of the respondents belonged to the age group of 31-36 years, while 72 respondents $(79.1 \%)$ were females. The majority of the respondents were employed as batik workers who worked at home and in the batik factories in Pekalongan City. They were 60 (65.9\%) in number and 38 of the respondents $(41.7 \%)$ had finished primary school or equivalent.

Table 2 shows that overall MDA drug compliance in 2014 was $86.8 \%$, whereas in 2015 it was $74.7 \%$. MDA respondents who had noncadres as drug compliance observers were more compliant in taking the MDA antifilarial drugs in 2014 and 2015, in comparison with respondents

Table 1. Distribution of sociodemographic characteristics of respondents $(n=91)$

\begin{tabular}{lc}
\hline Characteristics of respondents & n(\%) \\
\hline Age & $12(13.2)$ \\
$25-30$ & $18(19.8)$ \\
$31-36$ & $16(17.6)$ \\
$37-42$ & $17(18.7)$ \\
$43-48$ & $17(18.7)$ \\
$49-54$ & $7(7.7)$ \\
$55-60$ & $4(4.4)$ \\
$61-66$ & \\
Gender & $19(20.9)$ \\
Male & $72(79.1)$ \\
F em ale & \\
Occupation & $15(16.5)$ \\
Unemployed & $1(1.1)$ \\
Civil servants & $6(6.6)$ \\
Employees & $7(7.7)$ \\
Trader & $60(65.9)$ \\
B atik workers & $1(1.1)$ \\
Other workers & $1(1.1)$ \\
Entrepreneu & \\
Ed ucation & $13(14.3)$ \\
Did not finish frimary school & $38(41.7)$ \\
Finished prim ary shool/equivalent & $19(20.9)$ \\
Finished jurior high / quivalent & $20(22.0)$ \\
Finished senior high/equivalent & $1(1.1)$ \\
Finished academyhuniversity & \\
\hline
\end{tabular}


Table 2. Distribution of drug compliance in MDA program for 2014 and 2015, by type of drug compliance observer

\begin{tabular}{|c|c|c|c|c|c|c|c|c|c|c|c|c|}
\hline \multirow{4}{*}{ Variable } & \multicolumn{12}{|c|}{ Drug conp liance } \\
\hline & \multicolumn{6}{|c|}{2014} & \multicolumn{6}{|c|}{2015} \\
\hline & \multicolumn{2}{|c|}{$\mathrm{NC}$} & \multicolumn{2}{|c|}{$\mathrm{C}$} & \multicolumn{2}{|c|}{ Total } & \multicolumn{2}{|c|}{$\mathrm{NC}$} & \multicolumn{2}{|c|}{$\mathrm{C}$} & \multicolumn{2}{|c|}{ Total } \\
\hline & n & $\%$ & n & $\%$ & n & $\%$ & n & $\%$ & n & $\%$ & n & $\%$ \\
\hline \multicolumn{13}{|l|}{ Type DCO } \\
\hline N on-cadre & 1 & 3.3 & 29 & 96.7 & 30 & 100 & 2 & 6.7 & 28 & 93.3 & 30 & 100 \\
\hline Cade & 11 & 18.0 & 50 & 82.0 & 61 & 100 & 21 & 34.4 & 40 & 65.6 & 61 & 100 \\
\hline T otal & 12 & 13.2 & 79 & 86.8 & 91 & 100 & 23 & 25.3 & 68 & 74.7 & 91 & 100 \\
\hline
\end{tabular}

$\mathrm{DCO}=$ drug compliance observer; $\mathrm{NC}=$ noncompliant $; \mathrm{C}=$ compliant

whose drug compliance observers were cadres, with compliance rates of $96.7 \%$ in 2014 and $93.3 \%$ in 2015 .

The majority of the 91 respondents of the filariasis MDA program in 2014 and 2015, namely 61 respondents $(67 \%)$ had cadres as drug compliance observers, while the remainder (30 respondents or $33 \%$ ) had non-cadres originating from families as drug compliance observers. According to Table 3, the most frequent reason for MDA antifilariasis drug noncompliance in 2014 and 2015 was the fear of drug side effects, the percentage of responses being $50.0 \%$ and $39.1 \%$, respectively.

Table 4 shows that all variables, namely type of drug compliance observer, participation in counseling and presence of patients with filariasis in residential area were not significantly correlated with MDA drug compliance in 2014, with p values of $0.095,0.154$ and 0.757 , respectively. Similarly, for the MDA program in 2015, participation in counseling and the presence patients with filariasis in residential area were also not significantly correlated with MDA antifilariasis drug compliance, with $\mathrm{p}$ values of 0.325 and 1.000 , respectively. However, among the respondents with non-cadre observers, it was found that $93.3 \%$ of subjects complied in drug taking in 2015, which was significantly higher than the percentage of subjects with cadres as observers, their drug compliance being $65.6 \%$ ( $\mathrm{p}=0.009)$.

\section{DISCUSSION}

Filariasis mass drug administration is implemented in lymphatic filariasis endemic areas, which are areas with $\mathrm{mf}$ rates of approximately $1 \%$. The goal of mass drug administration is to simultaneously kill all microfilariae in the blood of every resident, so as to interrupt the transmission chain. Mass drug administration in the framework of lymphatic filariasis elimination aims to reduce the $\mathrm{mf}$ rate to less than $1 \%$ and to reduce the mean microfilarial density. Our study showed that following filariasis MDA in 2014, i.e. the $4^{\text {th }}$ annual round, there was a reduction in $\mathrm{mf}$ rate of $0.05 \%$, from $1.4 \%$ to $1.35 \%$, while in 2015

Table 3. Reasons for drug noncompliance in the MDA program for 2014 and 2015 ( $\mathrm{n}=91$ )

\begin{tabular}{llccc}
\hline \multirow{2}{*}{$\begin{array}{c}\text { Reason for antifilariasis d rug } \\
\text { no ncomp liance }\end{array}$} & \multicolumn{3}{c}{ Mass drug administration round } \\
\cline { 2 - 5 } & \multicolumn{2}{c}{ Years 2014 } & \multicolumn{2}{c}{ Y ears 2015 } \\
\cline { 2 - 5 } & $\mathbf{n}$ & 50.0 & 9 & $\mathbf{0}$ \\
\hline Fear of drug side effects & 6 & 16.7 & 2 & 39.1 \\
L a iness & 2 & 8.3 & 1 & 4.3 \\
No benefits & 1 & - & 3 & 13.0 \\
Forgetfulness & - & - & 2 & 8.7 \\
Did not received the dugs & - & 25.0 & 6 & 26.1 \\
Refusal & 3 & & & \\
\hline
\end{tabular}


Table 4. Relationship of type of drug compliance observers, counseling participation, and presence of filariasis patients in residential area with MDA drug compliance in 2014 and 2015

\begin{tabular}{|c|c|c|c|c|c|c|c|}
\hline \multirow{3}{*}{ Variables } & \multicolumn{4}{|c|}{ Drug compliance } & \multirow{2}{*}{\multicolumn{2}{|c|}{ Total }} & \multirow{3}{*}{$\mathbf{p}$} \\
\hline & \multicolumn{2}{|c|}{ Noncomp liant } & \multicolumn{2}{|c|}{ Conp liant } & & & \\
\hline & $\mathbf{n}$ & $\%$ & $\mathbf{n}$ & $\%$ & $\mathbf{n}$ & $\%$ & \\
\hline \multicolumn{8}{|l|}{2014} \\
\hline \multicolumn{8}{|l|}{ Type DCO } \\
\hline Non-cadre & 1 & 3.3 & 29 & 96.7 & 30 & 100.0 & \multirow{2}{*}{0.095} \\
\hline C adre & 11 & 18.0 & 50 & 82.0 & 61 & 100.0 & \\
\hline \multicolumn{8}{|c|}{ Participation in counseling } \\
\hline Never participated & 6 & 20.0 & 24 & 80.0 & 30 & 100.0 & \multirow{2}{*}{0.154} \\
\hline Participated & 6 & 9.8 & 55 & 90.2 & 61 & 100.0 & \\
\hline \multicolumn{8}{|c|}{$\begin{array}{l}\text { Presence of filariasispatients in } \\
\text { residential area }\end{array}$} \\
\hline Absent & 7 & 12.3 & 50 & 87.7 & 57 & 100.0 & \multirow{2}{*}{0.757} \\
\hline Present & 5 & 14.7 & 29 & 85.3 & 34 & 100.0 & \\
\hline \multicolumn{8}{|l|}{2015} \\
\hline \multicolumn{8}{|l|}{ Type DCO } \\
\hline Non-cadre & 2 & 6.7 & 28 & 93.3 & 30 & 100.0 & \multirow{2}{*}{0.009} \\
\hline C adre & 21 & 34.4 & 40 & 65.6 & 61 & 100.0 & \\
\hline \multicolumn{8}{|l|}{ Participation in caunseling } \\
\hline Never participated & 10 & 33.3 & 20 & 66.7 & 30 & 100.0 & \multirow{2}{*}{0.325} \\
\hline Participated & 13 & 21.3 & 48 & 78.7 & 61 & 100.0 & \\
\hline \multicolumn{8}{|c|}{$\begin{array}{l}\text { Presence of filariasispatients in } \\
\text { residential area }\end{array}$} \\
\hline Absent & 14 & 24.6 & 43 & 75.4 & 57 & 100.0 & \multirow{2}{*}{1.000} \\
\hline Present & 9 & 26.5 & 25 & 73.5 & 34 & 100.0 & \\
\hline
\end{tabular}

$\mathrm{DCO}=$ drug compliance observer

there was a reduction in $\mathrm{mf}$ rate of $23.70 \%$, from $1.35 \%$ to $0.32 \%$. These results signify that upon implementation of the MDA program in the $5^{\text {th }}$ year, the area in question had ceased to be a filariasis endemic area. The success of this filariasis elimination program was supported among other factors by the relatively high overall drug compliance level, i.e. $86.8 \%$ in 2014 and $74.7 \%$ in 2015. Kumar and Sachan state that filariasis mass drug administration using a combination of DEC and albendazole has the potential to attain the elimination target, if the drug coverage is more than $75 \%$. $^{(13)}$

The results of the present study are in line with the study by Kalimuthu et al., ${ }^{(14)}$ who state that following implementation of the fifth annual MDA round in South India, there was a reduction in $\mathrm{mf}$ rate of $72.5 \%$, supported by a drug compliance rate of $86.32 \%$. Vaishnav et al. ${ }^{(15)}$ reported on the success of a filariasis elimination program after implementation of 4 annual MDA rounds, with support from attainment of drug compliance of greater than $85 \%$. The success of this MDA program was supported by excellent preparation of activities, full government support, involvement of institutions of medical education, increased capacity of the executive team and evaluation of the impact through a survey. In contrast, Jones et al. ${ }^{(16)}$ state that implementation of an MDA program of up to 9 rounds, did not succeed in liberating Tanzania from its filariasis endemic status. Although there was a reduction in filarial antigen prevalence of $34.6 \%$, from $49 \%$ to $14.4 \%$, the presence of filarial antigen upon examination of the blood of the population showed that there still was active filariasis transmission in these areas. The continual transmission of filariasis was due to low drug compliance in its MDA program. The residents who were actively involved and complied in taking antifilariasis drugs accounted for less than $50 \%$ of the total number of residents. 
Drug noncompliance in the MDA program in the Pabean area was mostly caused by fear of drug side effects. The respondents were afraid of suffering from dizziness, nausea, and muscle pain after taking the drugs, causing them to be incapacited as batik factory workers, since nearly all were batik factory workers. The respondents were more concerned with the economic loss that they had to bear if they suffered from drug reactions after taking the antifilariasis drugs.

Kumar and Sachan stated that one of the reasons for failure to attain $100 \%$ compliance in consuming antifilariasis drugs in the MDA program is that the group of asymptomatic patients harboring microfilariae refuse to take antifilariasis drugs, because of the development of fever after ingesting DEC, which signifies inappropriate dissemination of information. ${ }^{(13)}$

Hussain et al. ${ }^{(10)}$ state that failure to attain drug compliance in the MDA program is due to absence of health personnel during distribution of antifilariasis drugs. Among 99\% of subjects who are recipients of antifilariasis drugs in India, only around $25 \%$ take the drugs, which agrees with the MDA program in the Pabean area of Pekalongan. The health personnel from the Puskesmas were not all present during the distribution of antifilariasis drugs to the residents and did not observe the taking of the antifilariasis drugs by the residents. Actually the antifilariasis drugs were handed over to the health cadres, to be subsequently distributed to the residents. ${ }^{(17-19)}$

The MDA program in the Pabean region used a combination of DEC, albendazole and paracetamol, administered once annually for a minimum of 5 years. The dose of DEC is $6 \mathrm{mg} /$ $\mathrm{kgBW}$, albendazole $400 \mathrm{mg}$ for all age groups, and paracetamol $10 \mathrm{mg} / \mathrm{kgBW}$. DEC kills microfilariae within several hours after being ingested. This is accomplished by paralyzing the microfilarial musculature, thus dislocating them from their normal habitat, and by altering the composition of the microfilarial surface membranes, so that they are readily destroyed by the host defense mechanisms. DEC is rapidly absorbed by the alimentary tract, reaches peak plasma concentrations after 4 hours, and is completely excreted in urine within 48 hours. Albendazole acts to kill adult filarial worms and enhance the effect of DEC in killing adult worms and microfilariae without additional adverse reactions. ${ }^{(20)}$

The drugs DEC and albendazole are safe drugs that are well-tolerated by most people. However, occasionally drug reactions may occur, particularly in infections with Brugia malayi and Brugia timori. The reactions may take the form of systemic and local reactions. Systemic reactions occur only within the first 3 days after taking of the drugs and are self-limited. They occur due to an individual's immune response against disintegrating microfilariae. The greater the number of disintegrating microfilariae, the more severe the reaction that may develop. Systemic reactions comprise headaches, fever, nausea, vomiting, muscle pains, joint pains, and itching. Local reactions against bancroftian filariasis are in the form of scrotal cutaneous nodules caused by dead adult worms, which is the most frequently occurring local reaction. In addition, lymphadenitis, lymphangitis, orchitis, abscess, ulceration, and lymphedema may occur. Local reactions are caused by the death of adult worms and may develop up to 3 weeks after mass drug administration. ${ }^{(5,16)}$

The presence of drug compliance observers, participation in counseling, and the presence patients with chronic filariasis in the residential area of the respondents are factors for which an association with antifilariasis drug compliance was investigated. In this study, drug observers are persons who remind the study subjects to take the antifilariasis drugs, who observe the taking of the drugs by the study subjects, and who report the development of side effects. Drug compliance observers in this study consisted of health cadres and non-cadres, the latter being family members. All study subjects who complied by ingesting the antifilariasis drugs in this study were accompanied by drug compliance observers (PMO).

Our study shows that among the subjects with non-cadre drug compliance observers, $93.3 \%$ 
were compliant in taking antifilariasis drugs in 2015, which was significantly higher than the subjects who had cadres as drug compliance observers, among whom only $65.6 \%$ were drugcompliant. To eliminate lymphatic filariasis from an endemic area within four to six annual rounds of MDA, at least $65 \%$ of the at-risk population should receive and take the recommended drugs (albendazole/ivermectin or albendazole/diethyl carbamazine) under directly observed therapy. ${ }^{(21)}$

The filariasis elimination effort through the MDA program requires the involvement and compliance of all community members in endemic areas, especially among the households. The presence of residents who are not taking drugs in the filariasis MDA program may constitute a possible source of microfilariae for other individuals and for the mosquito vectors. Therefore it essential that all household and community members have an attitude of mutual interest and accountability in drug compliance. This is particularly true since the MDA program is carried out for 4-6 years, corresponding to the reproductive period of the adult worms. This long period will inevitably lead to feelings of being fed up and bored, particularly those who do not feel the direct benefits of the treatment. Thus there is a need for reciprocal support and reminding between household and community members in endemic areas that the filariasis elimination effort is a common responsibility.

The effort to delve into the reasons for noncompliance in taking antifilariasis drugs using the interview technique constitutes a limitation of this study, particularly for study subjects who refuse to take the antifilariasis drugs. The presence of noncompliant residents in taking antifilariasis drugs during the filariasis MDA program in Pekalongan City, will particularly result in the possibility of a continued presence of sources of filarial infection, which may inhibit the filariasis elimination effort in this area.

Further studies on the reasons for drug noncompliance in the filariasis MDA program should use a qualitative study design involving antifilariasis drug noncompliant subjects by means of in-depth interviews.

\section{CONCLUSIONS}

In 2014 there was a reduction in $\mathrm{mf}$ rate of $0.05 \%$, from $1.4 \%$ to $1.35 \%$, and in 2015 a reduction in $\mathrm{mf}$ rate of $23.70 \%$, from $1.35 \%$ to $0.32 \%$. The presence of drug compliance observers from the family circle is the most important variable associated with antifilariasis drug compliance.

\section{CONFLICT OF INTERESTS}

The investigators state that they had no conflict of interest in this study.

\section{ACKNOWLEDGEMENT}

The investigators express their gratitude to the Health Service of Pekalongan City, the head of Dukuh puskesmas and staff, to th health cadres of the Pabean area who assisted in this study, especially in mobilizing the residents for the filariasis fingerprick blood survey.

\section{REFERENCES}

1. World Health Organization. Progress report 2000-2009 and strategic plan 2010-2020 of the global program to eliminate lymphatic filariasis: halfway towards eliminating lymphatic filariasis. Geneva: World Health Organization;2010.

2. Kementrian Kesehatan RI. Epidemiologi penyakit kaki gajah (filariasis) di Indonesia. Jakarta: Ditjen PP \& PL Kemenkes RI;2009.

3. Ramdhani T, Soeyoko, Sumarni S. Culex quinquefasciatus sebagai vektor utama filariasis limfatik yang disebabkan Wuchereria bancrofti di kelurahan Pabean Kota Pekalongan. J Ekol Kes 2010;9:1303-10.

4. de Souza DK, Koudou B, Kelly-Hope LA, et al. Diversity and transmission competence in lymphatic filariasis vectors in West Africa, and the implications for accelerated elimination of Anopheles-transmitted filariasis. Parasit Vectors 2012;5:259. 
5. Kementerian Kesehatan RI. Pengobatan masal filariasis. Jakarta: Ditjen PP \& PL Kemenkes RI; 2009.

6. Nujum ZT. Coverage and compliance to mass drug administration for lymphatic filariasis elimination in a district of Kerala, India. Int Health 2011;3:22-6.

7. Koroma JB, Sesay S, Sonnie M, et al. Impact of three rounds of mass drug administration on lymphatic filariasis in areas previously treated for onchocerciasis in Sierra Leone. PLoS Negl Trop Dis 2013;7:e2273.

8. Eigege A, Kal A, Miri E, et al. Long-lasting insecticidal nets are synergistic with mass drug administration for interruption of lymphatic filariasis transmission in Nigeria. PloS Negl Trop Dis 2013; 7:e2508.

9. Babu BV, Babu GR. Coverage of and compliance with mass drug administration under the programme to eliminate lymphatic filariasis in India: a systematic review. Trans R Soc Trop Med Hyg 2014;108:538-49.

10. Hussain MA, Sitha AK, Swain S, et al. Mass drug administration for lymphatic filariasis elimination in a coastal state of India: a study on barriers to coverage and compliance. Infect Dis Poverty 2014;3:31.

11. Lwanga SK, Lemeshow S. Sample size determination in health studies: a practical manual. Geneva: World Health Organization; 1991.

12. Sugiyono. Metode penelitian kuantitatif, kualitatif dan R \& D. Bandung: CV.Alfabeta; 2011.

13. Kumar A, Sachan P. Measuring impact on filarial infection status in a community study : role of coverage of mass drug administration. Tropical Biomedicine 2014;31:225-9.
14. Kalimuthu M, Sunish IP, Nagaraj J, et al. Residual microfilaremia in rural pockets of South India after five rounds of DEC plus albendazole administration as part o the LF elimination campaign. J Vector Borne Dis 2015;52;182-4.

15. Vaishnav KG, Desai HS, Srivastava PK, et al. Impact of mass drug administration on elimination of lymphatic filariasis in Surat City India. J Comm Dis 2012;44:251-9.

16. Jones C, Tarimo DS, Malecela MN. Evidence of contiuned transmission of Wuchereria bancrofti and associated factors despite nine rounds of ivermectin and albendazole mass drug administration in Rufiji district Tanzania. Tanzania J Health Res 2015;17:1-9.

17. World Health Organization. Global programme to eliminate lymphatic filariasis: progres report 2014. Weekly Epidemiol Rec 2015;90:489-504.

18. Krentel A, Fischer PU, Weil GJ. A review of factors that influence individual compliance with mass drug administration for elimination of lymphatic filariasis. PloS Negl Trop Dis 2013;7: e2447.

19. Ghosh S, Samantha A, Kole S. Mass drug administration for elimination of lymphatic filariasis: recent experiences from a district of West Bengal, India. Trop Parasitol 2013;3:6771.

20. Fernando SD, Rodrigo C, Rajapakse S. Current evidence on the use of antifilarial agents in the management of bancroftian filariasis. J Trop Med 2011, Article ID 175941, 12 pages. doi: 10.1155/ 2011/175941.

21. Offei M, Anto F. Compliance to mass drug administration programme for lymphatic filariasis elimination by community members and volunteers in the Ahanta West District of Ghana. J Bacteriol Parasitol 2014;5:180. doi: 10.4172/2155-9597.1000180. 